\title{
Current status of lung transplantation in Japan-report from Japanese lung transplant registry
}

\author{
Yoshinori Okada ${ }^{1}$, Masayuki Chida ${ }^{2}$, June Nakajima ${ }^{3}$, Ichiro Yoshino ${ }^{4}$, Yasushi Shintani ${ }^{5}$, Takahiro Oto ${ }^{6}$, \\ Takeshi Shiraishi $^{7}$, Takeshi Nagayasu ${ }^{8}$, Hiroshi Date ${ }^{9}$
}

${ }^{1}$ Department of Thoracic Surgery, Tohoku University, Sendai, Japan; ${ }^{2}$ Department of General Thoracic Surgery, Dokkyo Medical University, Tochigi, Japan; ${ }^{3}$ Department of Thoracic Surgery, The University of Tokyo, Tokyo, Japan; ${ }^{4}$ Department of General Thoracic Surgery, Chiba University, Chiba, Japan; ${ }^{5}$ Department of General Thoracic Surgery, Osaka University, Osaka, Japan; ${ }^{6}$ Department of Organ Transplant Center, Okayama University, Okayama, Japan; ${ }^{7}$ Division of Thoracic Surgery, Fukuoka University, Fukuoka, Japan; ${ }^{8}$ Department of Surgical Oncology, Nagasaki University, Nagasaki, Japan; ${ }^{9}$ Department of Thoracic Surgery, Kyoto University, Kyoto, Japan

Contributions: Contributions: (I) Conception and design: All authors; (II) Administrative support: None; (III) Provision of study materials or patients: All authors; (IV) Collection and assembly of data: Y Okada; (V) Data analysis and interpretation: Y Okada; (VI) Manuscript writing: All authors; (VII) Final approval of manuscript: All authors.

Correspondence to: Yoshinori Okada, MD. Department of Thoracic Surgery, Institute of Development, Aging and Cancer, Tohoku University, 4-1 Seiryo-machi, Aoba-ku, Sendai 980-8575, Japan. Email: yoshinori.okada.a1@tohoku.ac.jp.

\begin{abstract}
Lung transplantation has been established as an effective treatment for end-stage lung diseases since the first success in 1983 . Today, more than 4,500 surgeries are performed annually and the cumulative number of cases is approximately 65,000 for adult lung transplants alone in the world. In Japan, the first living-donor lobar lung transplantation and the first cadaveric-donor lung transplantation were performed in 1998 and 2000, respectively. By the end of 2018, 447 cadaveric-donor lung transplants (231 single and 216 bilateral) and 221 living-donor lobar lung transplants (34 unilateral and 187 bilateral) have been performed and registered to the Japanese lung transplant registry. The main primary diseases for lung transplantation in Japan are idiopathic interstitial pneumonia, pulmonary arterial hypertension, lymphangioleiomyomatosis and lung dysfunction after hematopoietic stem cell transplantation. The 5-year survival rate in the international registry is $55 \%$, while that of cadaveric-donor and living-donor lung transplantation in Japan is $72 \%$ and $74 \%$, respectively. Main causes of death after lung transplantation consist of infection, primary graft dysfunction and chronic lung allograft dysfunction also in Japan as the international registry shows. Establishment of prevention/treatment modalities for these complications is particularly important for further improvement in outcome of lung transplant recipients.
\end{abstract}

Keywords: Cadaveric-donor lung transplantation; living-donor lobar lung transplantation; brain-death; Japanese organ transplantation law

Received: 31 January 2020; Accepted: 12 March 2020; Published: 20 April 2021.

doi: 10.21037 /jovs.2020.03.06

View this article at: http://dx.doi.org/10.21037/jovs.2020.03.06

\section{Introduction}

Following the first success in 1983 by Toronto Lung Transplant Program, lung transplantation spread rapidly worldwide in the 1990s. Although the number of procedures appeared to have reached a plateau in the late 1990s, it began to increase again in the 2000s, and more than 4,500 lung transplant procedures are performed annually in recent years (1). In Japan, the start of clinical lung transplantation was delayed about 15 years compared to North America and Europe due to the delay in establishment of social consensus to accept brain death. However, after the enforcement of the Organ Transplantation Law in 1997, the first livingdonor lobar lung transplantation and the first cadaveric- 


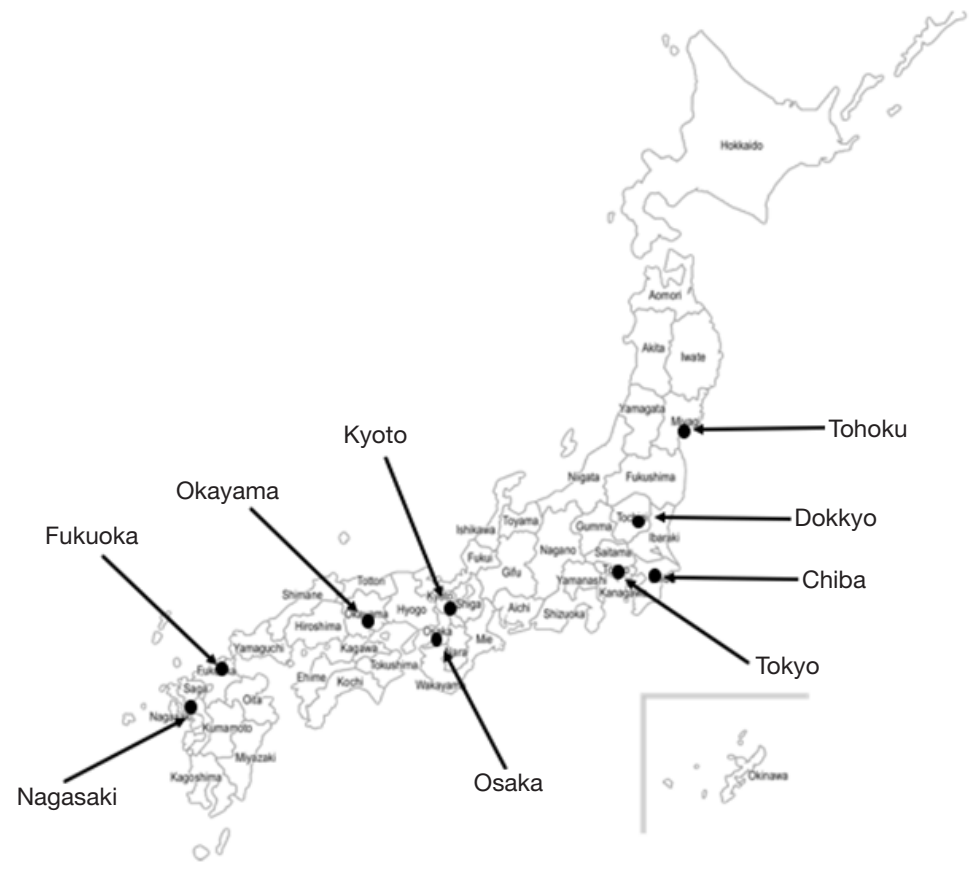

Figure 1 Lung transplant centers in Japan.

donor lung transplantations were performed in 1998 and 2000, respectively. After these first successful experiences, however, the annual number of lung transplantations in Japan had been about 10 to 15 cases a year given the scarce number of organ donations from brain-dead donors. As the revised Organ Transplant Law was enforced in 2010 and the number of organ donations under brain death has been increasing after that, the number of cadaveric-donor lung transplantation has also been increasing (2). This article describes the current status of lung transplantation in Japan based on the Japanese lung transplant registry.

\section{Current status of lung transplantation in Japan}

\section{History of lung transplantation in Fapan}

Although the start of organ transplantation in Japan delayed compared to North America and Europe due to the delay in establishment of social consensus to accept brain death, the Organ Transplant Law was eventually enforced in October 1997 and it has become legally possible to transplant organs from cadaveric-donor donors including those under brain death. The first living-donor lobar lung transplantation in Japan was performed at Okayama University (3) in 1998, and the first single lung transplantations from a braindead donor were performed at Tohoku University (4) and
Osaka University (5) in 2000. However, the number of lung transplantations in Japan had been limited to about 10 to 15 cases a year given the scarce number of organ donations from brain-dead donors under the law, requiring the written intention for organ donation during the lifetime and limiting organ donors to those aged 15 and over. However, in response to the Istanbul Declaration on Organ Trade and Transplantation Tourism by the International Society for Transplantation in 2008 that proposes banning organ trading and transplant tourism, promoting organ transplantation in its own country, and protecting living donors, the revised Organ Transplant Law was enforced in July 2010 in Japan. As a result, organ donation under brain death became possible with family consent regardless of the presence of written intension of organ donation and the age of the donors. With the increase in the number of organ donation following the enforcement of the revised law, the number of cadaveric-donor lung transplants also increased, 59 cadaveric-donor and 12 living-donor lobar lung transplantation were performed in 2018, which reached a record high as an annual number of the lung transplant procedures (2). As of the end of 2019, certified facilities for lung transplantation are affiliated hospitals of Tohoku University, Dokkyo Medical University, University of Tokyo, Chiba University, Kyoto University, Osaka University, Okayama University, Fukuoka University, 


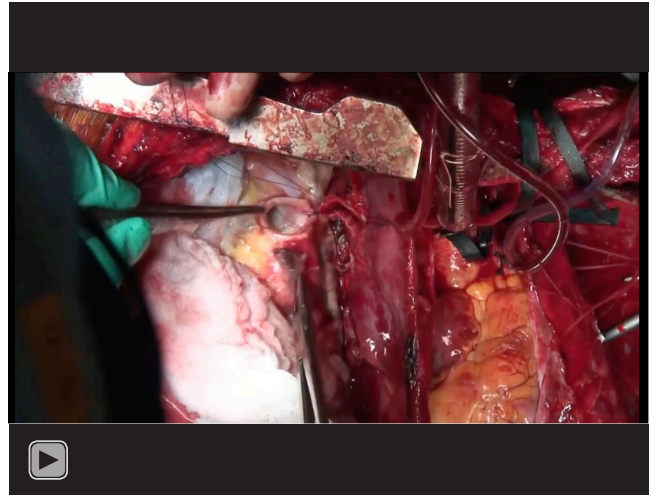

Video 1 Right Bronchial anastomosis. Bronchial anastomosis was performed with a continuous suture for membranous portion followed by interrupted suture for cartilaginous portion with 4-0 monofilament absorbable sutures. Telescope fashion was employed in this case.

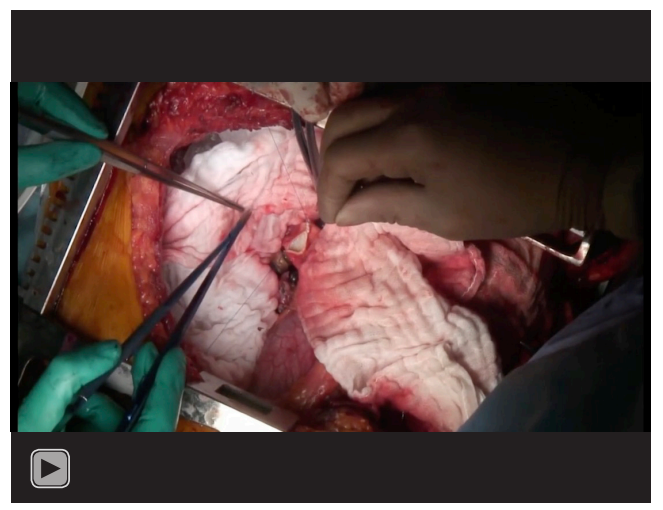

Video 2 Right pulmonary artery anastomosis. Pulmonary artery anastomosis was performed with a simple continuous suture with 6-0 monofilament non-absorbable sutures.

Nagasaki University, there are 9 centers in total (Figure 1). Usual procedures of the anastomosis of the right bronchus, the right pulmonary artery, and right pulmonary vein were shown in Videos 1-3.

\section{Number of lung transplant procedures}

Figure 2 shows the yearly trends in the number of lung transplant candidates newly registered to the Japan Organ Transplant Network. From 2001 to 2010, about 20 to 30 lung transplant candidates were registered annually. However, the number of registered patients increased from 2011, the year following the enforcement of the revised

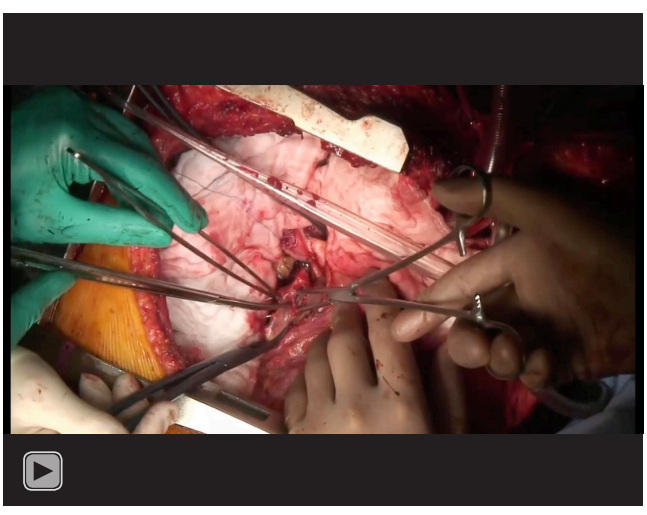

Video 3 Right pulmonary vein anastomosis. Staple lines of the right superior and inferior veins were amputated and the bridge of them was transected to prepare atrial cuff for anastomosis in the recipient. Then left atrium cuffs of the donor and recipient were anastomosed with a continuous suture with 5-0 monofilament nonabsorbable sutures.

Organ Transplant law and 139 lung transplant candidates were registered in 2018. With the increase in the number of organ donations under the revised law, the number of lung transplants also increased, and in 2018, a record number of 59 cadaveric-donor lung transplants were performed annually (Figure 3). As of the end of 2018, the total number of lung transplants in Japan was 671 (3 heart-lung transplants, 231 cadaveric-donor single lung transplants, 216 cadaveric-donor bilateral lung transplants and 221 living-donor lobar lung transplants). Table 1 shows the number of lung transplant cases for each facility. In 2018, the experience of cadaveric-donor lung transplantation in some institutions has reached more than 100 cases.

\section{Primary diseases of lung transplants in fapan}

Primary diseases of lung transplant recipients are shown in Figure 4. The most common primary disease as of the end of December 2018 is idiopathic interstitial pneumonia, followed by primary pulmonary hypertension, lymphangioleiomyomatosis and lung dysfunction after hematopoietic stem cell transplantation.

\section{Survival rate of recipient}

Survival rates of lung transplant recipients by surgical procedure types in Japan are shown in Figure 5. The 5- and 10 -year survival rates for cadaveric-donor lung transplant recipients were $71.9 \%$ and $57.8 \%$, respectively, exceeding 


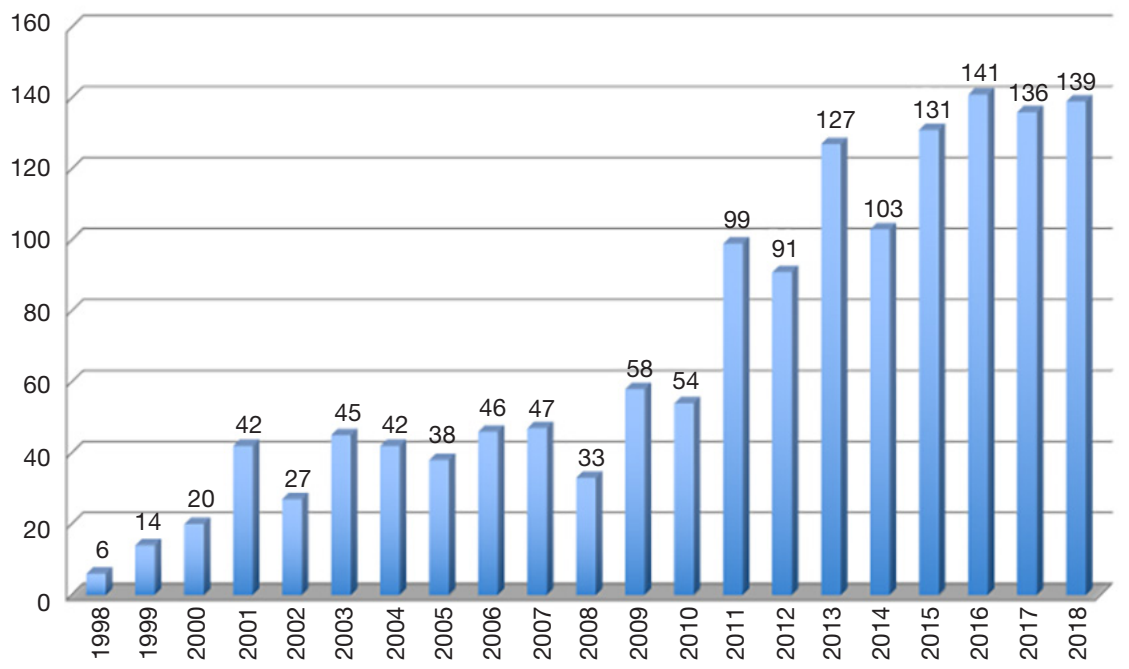

Figure 2 The number of lung transplant candidates newly registered to the Japan Organ Transplant Network. With permission from (2).
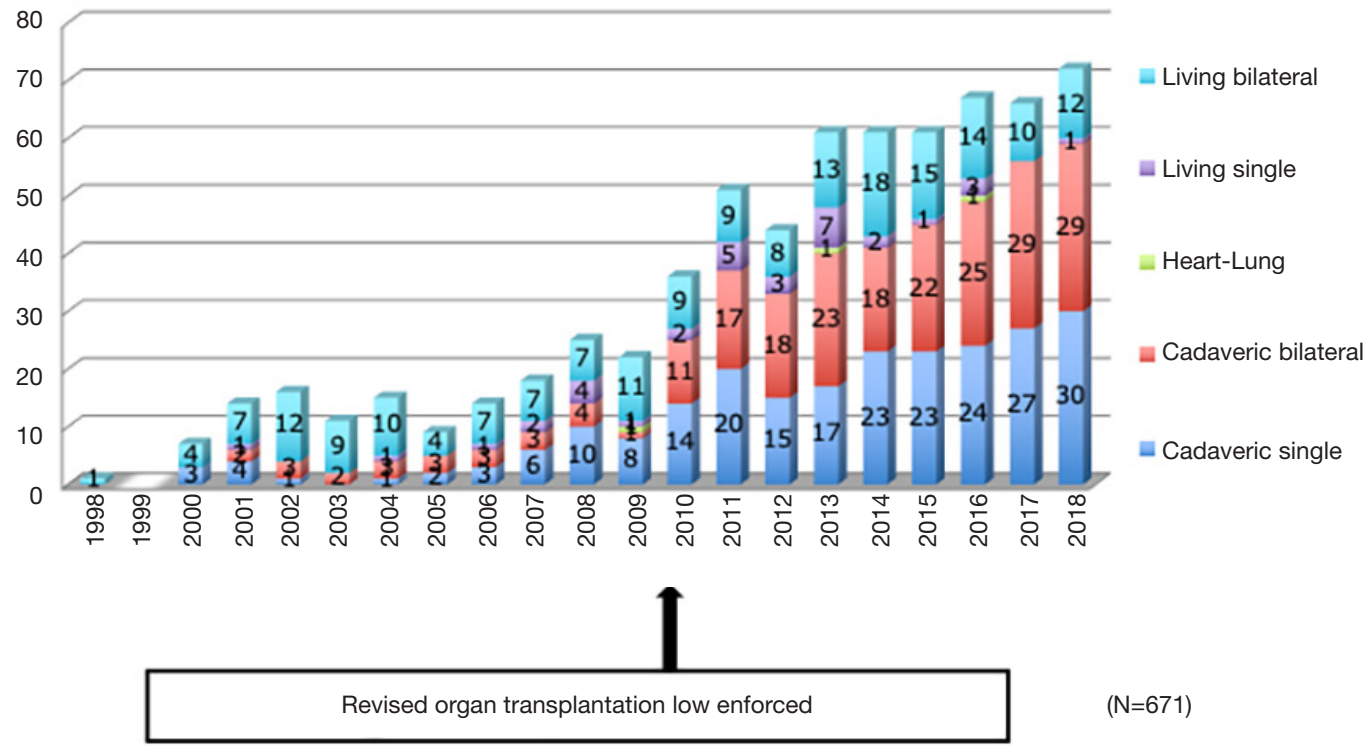

$(\mathrm{N}=671)$

Figure 3 Number of lung transplants by year and procedure type in Japan. With permission from (2).

the result of the international registry $(55.0 \%$ and $33.3 \%$, respectively). The 5- and 10-year survival rates for livingdonor lobar transplant recipients were $74.0 \%$ and $63.3 \%$, respectively, which are comparable to those of cadavericdonor lung transplant recipients. Three heart-lung transplant recipients were all alive.

\section{Working status of lung transplant recipients in Japan}

About $80 \%$ of recipients with cadaveric-donor and living- donor lung transplantation were involved in full-time work, part-time work, housework, or study in school, and only $20 \%$ of the patients were in home remedy or hospitalization (Figure 6).

\section{Cause of death of lung transplant recipients in Japan}

Cause of death of lung transplant recipients were analyzed with 175 recipients who died after cadaveric-donordonor $(n=109)$ or living-donor $(n=66)$ lung transplantation 
Table 1 Number of procedures by transplant centers in Japan

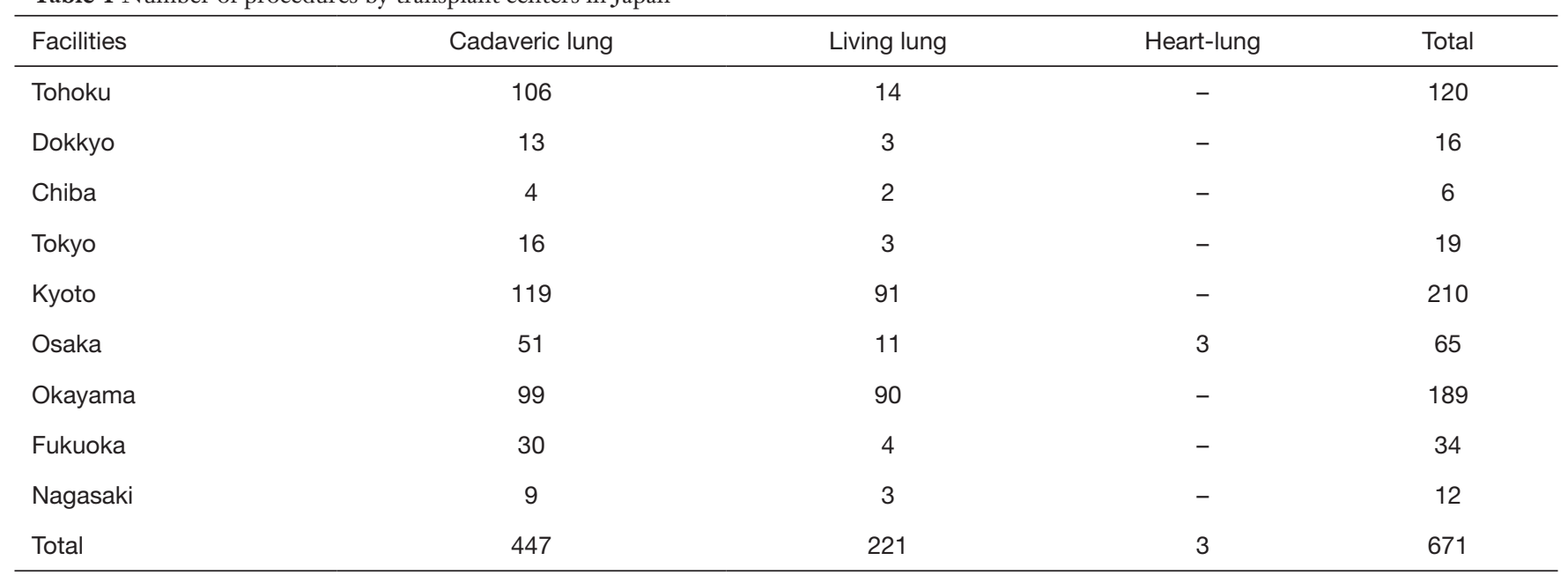

Transplants: October 1998 - December 2018. With permission from (2).

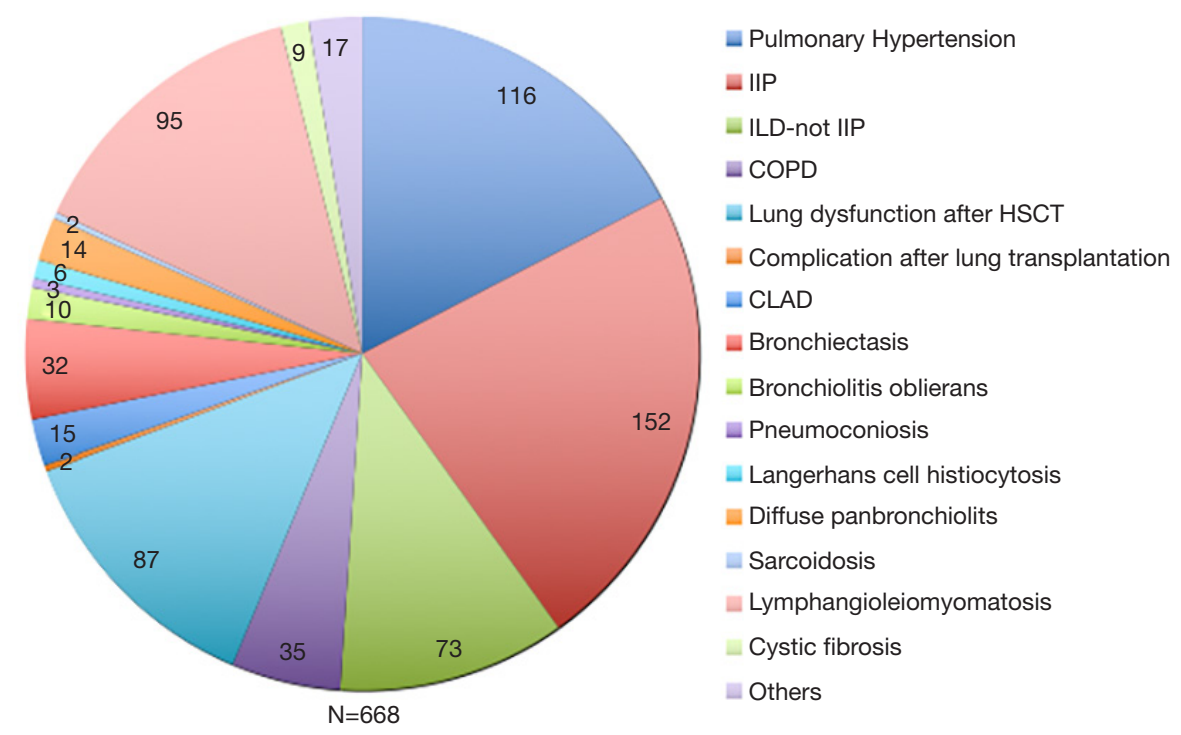

Figure 4 Primary diseases of lung transplants in Japan (transplants: October 1998 - December 2018). IIP, idiopathic interstitial pneumonia; ILD, interstitial lung disease; COPD, chronic obstructive pulmonary disease; HSCT, hematopoietic stem cell transplantation; CLAD, chronic lung allograft dysfunction.

(Figure 7). The leading cause of death were infection, accounting for $30 \%$ of all deaths in both cadaveric-donor or living-donor lung transplants, followed by primary graft dysfunction, chronic lung allograft dysfunction and malignancy other than post-transplant lymphoproliferative disorders. Distribution of causes of death was quite similar between cadaveric-donor and living-donor lung transplant recipients.

\section{Discussion}

Lung transplantation has been considered one of the most difficult organ transplant given the nature of the organ susceptible to allograft rejection and infection. The outcome of Japanese lung transplantation, however, has been so far good with a 5 -year survival rate of more than $70 \%$ for both cadaveric-donor and living-donor lobar lung 


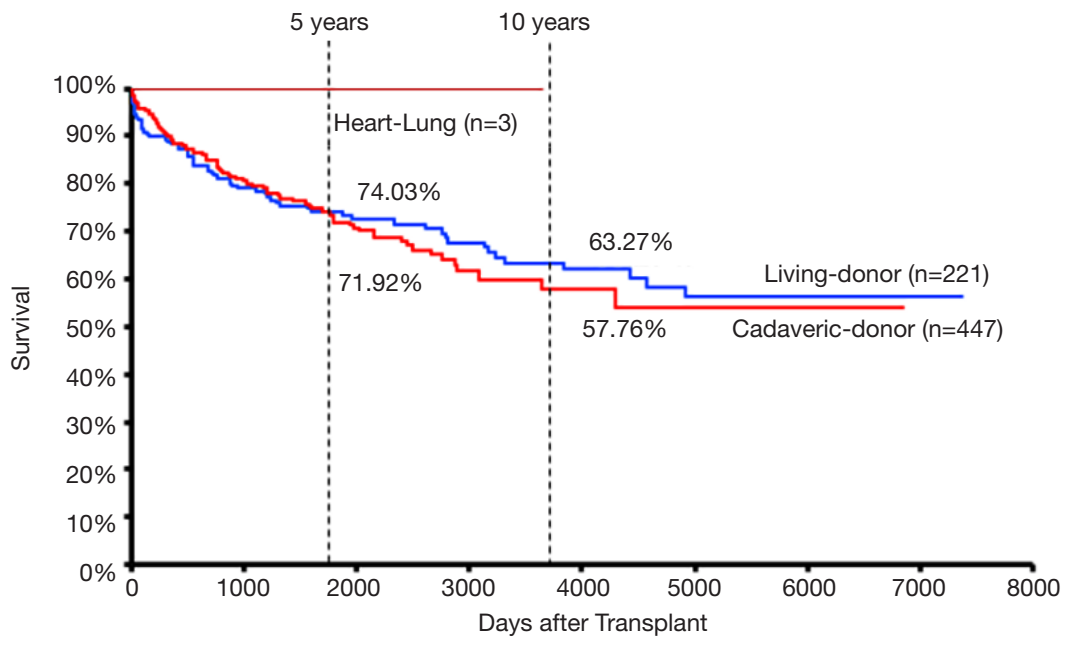

Figure 5 Kaplan-Meier survival for lung transplant recipients by 3 procedure types in Japan (transplants: October 1998 - December 2018). With permission from (2).
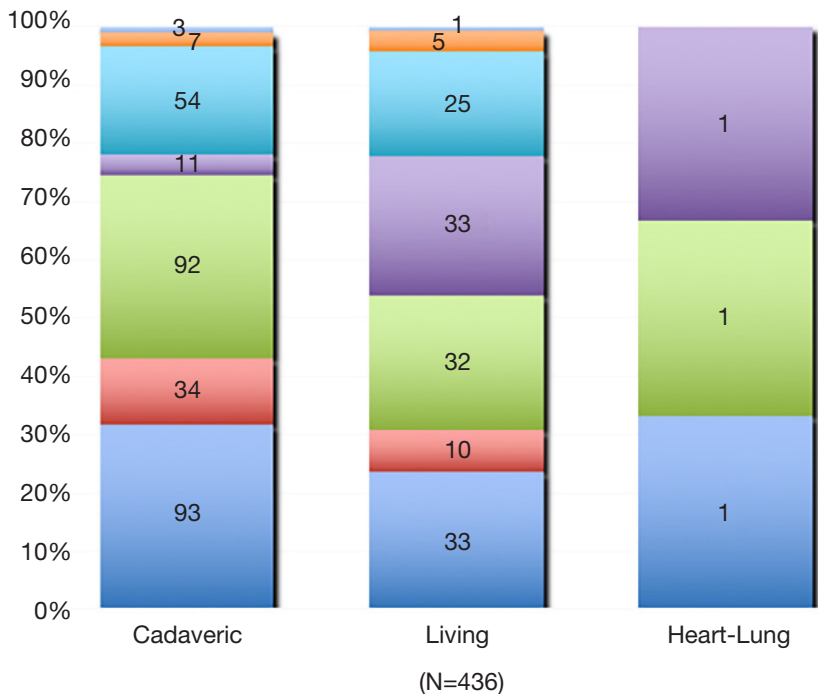

$$
\begin{aligned}
& \text { athers } \\
& \text { - Hospitalization } \\
& \text { ఐ Home remedy } \\
& \text { = Going to school } \\
& \text { - Housework } \\
& \text { — Part-time work }
\end{aligned}
$$

Figure 6 Post-transplant working status of lung transplant recipients in Japan (transplants: October 1998 - December 2018). With permission from (2).

transplantations. However, the number of organ donation under brain death in Japan is significantly smaller than that in the North America, Europe, or Asian countries such as China and South Korea, and cumulative number of death on the waiting list was $551(38.3 \%)$ of all number of registration in Japan (Figure 8). Thus, it is particularly necessary to further improve the social environment related to organ donation and organ transplantation. In addition, infection, primary graft dysfunction which is mostly related to ischemia-reperfusion lung injury, and chronic lung allograft dysfunction are also serious complications comprising major causes of death after lung transplantation in Japan as the international registry shows. Further progress in basic and clinical research to overcome these complications will be important for further improvement in outcome of lung transplant recipients. 

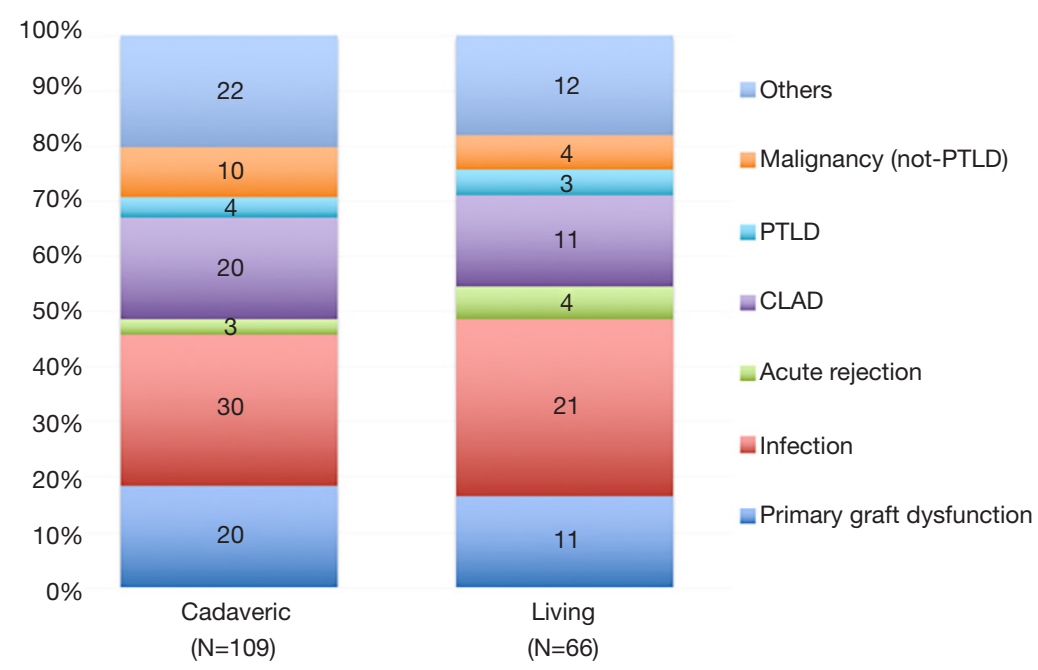

Figure 7 Causes of death after lung transplantation in Japan (transplants: October 1998 - December 2018). With permission from (2). PTLD, post-transplant lymphoproliferative disorder; CLAD, chronic lung allograft dysfunction.

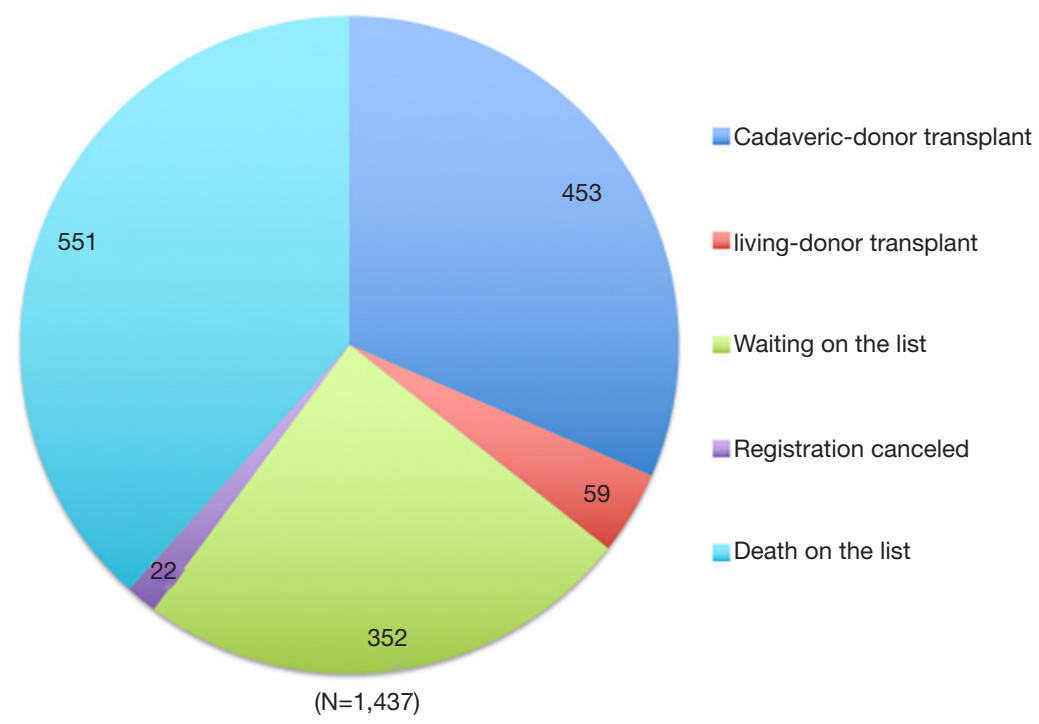

Figure 8 Outcome of lung transplant candidates registered to the Japan Organ Transplant Network. Cumulative number of death on the waiting list was $551(38.3 \%)$ of all number of registration.

\section{Acknowledgments}

We are grateful to recipient coordinators of 9 lung transplant facilities for their cooperation on establishing Japanese registry data.

Funding: None.

\section{Footnote}

Provenance and Peer Review: This article was commissioned by the Guest Editor (Meinoshin Okumura) for the series "Dedicated to the 36th Annual Conference of Japanese Association for Chest Surgery (JACS)" published in Fournal of Visualized Surgery. This article has undergone external peer review.

Conflicts of Interest: All authors have completed the ICMJE uniform disclosure form (available at https://jovs. amegroups.com/article/view/10.21037/jovs.2020.03.06/ 
coif). The series "Dedicated to the 36th Annual Conference of Japanese Association for Chest Surgery (JACS)" was commissioned by the editorial office without any funding or sponsorship. The authors have no other conflicts of interest to declare.

Ethical Statement: The authors are accountable for all aspects of the work in ensuring that questions related to the accuracy or integrity of any part of the work are appropriately investigated and resolved. All procedures performed in this study were in accordance with the Helsinki Declaration (as revised in 2013). The manuscript is waived from patient informed consent according to the ethics committee or institutional review board.

Open Access Statement: This is an Open Access article distributed in accordance with the Creative Commons Attribution-NonCommercial-NoDerivs 4.0 International License (CC BY-NC-ND 4.0), which permits the noncommercial replication and distribution of the article with the strict proviso that no changes or edits are made and the original work is properly cited (including links to both the formal publication through the relevant DOI and the license). See: https://creativecommons.org/licenses/by-nc-nd/4.0/.

\section{References}

1. Home page of the International Society for Heart and Lung Transplantation on the Internet. Available online: http://www.ishlt.org/

2. The Japanese Society of Lung and Heart-Lung Transplantation. Registry Report of Japanese Lung Transplantation-2019. Japanese Journal of Transplantation 2019;54:105-10.

3. Date H, Nagahiro I, Aoe M, et al. Living-donor lobar lung transplantation for primary pulmonary hypertension in an adult. J Thorac Cardiovasc Surg 2001;122:817-8.

4. Matsumura Y, Okada Y, Sado T, et al. First lung transplantation from brain-dead donor-right single lung transplant. Transplantation Now 2000;13:418-25.

5. Miyoshi S, Minami M, Ohta M, et al. Single lung transplantation from a brain-dead donor for a patient with idiopathic pulmonary fibrosis. A breakthrough after new legislation in Japan. Jpn J Thorac Cardiovasc Surg 2001;49:398-403. doi: 10.21037/jovs.2020.03.06

Cite this article as: Okada Y, Chida M, Nakajima J, Yoshino I, Shintani Y, Oto T, Shiraishi T, Nagayasu T, Date H. Current status of lung transplantation in Japan-report from Japanese lung transplant registry. J Vis Surg 202 1;7:13. 